\title{
Wound healing activity of Cleome rutidosperma DC. roots
}

\author{
* Sumanta Mondal and Padilam Suresh \\ GITAM Institute of Pharmacy, GITAM University, Gandhi Nagar, Visakhapatnam-530 045, Andhra Pradesh, India
}

\begin{abstract}
The petroleum ether, chloroform, methanol and aqueous extracts of Cleome rutidosperma DC (Family: Capparidaceae) roots were evaluated for their wound healing activities in rats using excision and incision wound models respectively. The effects of test samples on the rate of wound healing were assessed by the rate of wound closure, period of epithelialisation and wound breaking strength. Nitrofurazone $(0.2 \% \mathrm{w} / \mathrm{w})$ in simple ointment I.P. was used as reference standard for the activity comparison. The results of the study revealed that the animals treated with methanol and aqueous extracts of C. rutidosperma showed faster rate of wound healing compared to other extracts under study. The chloroform extract of the selected plant also produced promising results but the effects are seen to be of lesser extent than the corresponding methanol and aqueous extracts. The petroleum ether extract did not produce significant results. The present work justifies the use of C. rutidosperma roots for wound healing activity as claimed in the folklore literature.
\end{abstract}

Key Words: Cleome rutidosperma DC, wound healing activity, nitrofurazone, excision wound, incision wound.

\section{INTRODUCTION}

Wound healing is the process of repair that follows injury to the skin and proper healing of wounds is essential for the restoration of disrupted anatomical continuity and distrubed functional status of the skin (Karodi et al., 2009). Several medicinal plants have been used since time immemorial for treatment of cuts, wounds and burns and showed promising effects. Some very common plants like Aloe vera, Azadirachta indica, Carica papaya, Celosia argentea, Centella asiatica, Cinnamomum zeylanicum, Curcuma longa, Nelumbo nucifera, Ocimum sanctum, Phyllanthus emblica, Plumbago zeylanica, Pterocarpus santalinus, Terminalia arjuna and Terminalia chebula have been extensively reported in Ayurveda, Siddha and Unani systems of medicines for their wound healing potential (Kumar et al., 2007).

Cleome rutidosperma DC (Family: Capparidaceae) is a low-growing herb, up to $70 \mathrm{~cm}$ tall with trifoliate roots and small violet-blue flowers, which turn pink as they age, found in waste grounds and grassy

\footnotetext{
*Corresponding Author:

Dr. Sumanta Mondal, Lecturer

GITAM Institute of Pharmacy, GITAM University

Gandhi Nagar, Rushikonda, Visakhapatnam-530 045

Andhra Pradesh, India

E-mail: phytochemistry@rediffmail.com

Contact No.: +91-9703615761
}

places. The plant is native to West Africa and has become naturalized in various parts of tropical America as well as South East Asia (Widespread, 1972; Waterhouse, 1998). Traditionally, the roots, leaves and seeds of the plants of Cleome genus are used as stimulant, antiscorbutic, anthelmintic, rubifacient, vesicant and carminative (Kiritikar and Basu, 1991). In Malaysia, planting of C. rutidosperma around field edges may be considered as part of an insect control programmed (Burkill, 2004). The antiplasmodial activity of the chloroform-methanol (1:1) extract of the leaves was reported by Bidla et al. (2004), simmilarly diuretic, laxative, analgesic, antiinflammatory, antipyretic, antimicrobial, antioxidant and free radical scavenging activities of the aerial parts of C. rutidosperma have been reported earlier (Bose et al., 2008). The roots are also reported to have hypoglycaemic effect (Mondal et al., 2009) and anthelmintic activity (Mondal et al., 2009).

As per the folklore information the tribal people apply the juice of roots over severe open wounds and claim for its promising effectiveness towards healing of wounds, so in the present study was undertaken to provide on wound healing activity of the roots using all possible models and provide a scientific support to its use in the folklore medicines for treating wound infection. 


\section{MATERIALS AND METHODS}

\section{Plant Material}

The plant material (roots) were collected from the rural belt of Vishakhapatnam district of Andhra Pradesh during November 2011 and authenticated. The roots were washed, shade dried and pulverized to coarse powder. The powdered roots $(500 \mathrm{~g})$ were successively extracted with petroleum ether (40$60^{\circ} \mathrm{C}$ ), chloroform, methanol and water for $48 \mathrm{~h}$ in a soxhlet extractor. Following extraction, the liquid extracts were concentrated under vacuum to yield dry extracts. Standard methods (Harborne, 1984; Trease and Evans, 1989) were used for preliminary phytochemical screening of the different extracts to know the nature of phytoconstitutents present within them.

\section{Animals}

Healthy Wistar albino rats (150-250 g) of either sex and of approximately the same age were used for the study. They were individually housed, maintained in clean polypropylene cages and fed with commercially pellet diet (M/s Hindustan Lever Ltd., Mumbai) and water ad libitum. The experimental protocols were subjected to scrutiny of Institutional Animal Ethics Committee for experimental clearance (Protocol No.: IAEC/GIP-1287/M Pharm/IP/SM-SA/2011-12). Six groups, each containing six animals were used for each of the excesion and incision woun models. A $10 \% \mathrm{w} / \mathrm{w}$ of the test extracts in simple ointment I.P. was applied topically for each animal once daily (morning).

\section{Excision Wound Model (Normal wounds)}

Animals were anesthetized prior to and during creation of the wounds, with $1 \mathrm{ml}$ of intravenous ketamine hydrochloride $(10 \mathrm{mg} / \mathrm{kg})$. The rats were inflicted with excision wounds as described by
Morton and Malone (1972) and suggested by Kamath et al. (2003). An impression was made on the dorsal thoracic region $1 \mathrm{~cm}$ away from vertebral column and $5 \mathrm{~cm}$ away from ear on the anaesthetized rat. The dorsal fur of the animals was shaved with an electric clipper and the anticipated area of the wound to be created was outlined on the back of the animals with methylene blue using a circular stainless steel stencil. A full thickness of the excision wound of circular area of $500 \mathrm{~mm}^{2}$ and $2 \mathrm{~mm}$ depth was created along the markings using toothed forceps, scalpel and pointed scissors. Haemostasis was achieved by blotting the wound with cotton swab soaked in normal saline. The entire wound was left open (James and Friday, 2010). All surgical procedures were performed under aseptic conditions.

The control group animals (Group I) were treated with the vehicle (Simple ointment I.P.), the positive control (Group II) was applied with $0.2 \% \mathrm{w} / \mathrm{w}$ nitrofurazone in simple ointment I.P. Other groups of animals were treated with the following: petroleum ether, chloroform, methanol or aqueous extracts of C. rutidosperma at a concentration of $10 \%$ $\mathrm{w} / \mathrm{w}$ in simple ointment I.P. in a similar manner.

The wound closure rate was assessed by tracing the wound on days $1,4,7,10,13$ and 16 post wounding days using transparent paper and a permanent marker. The wound areas recorded were measured using graph paper (Fulzele et al., 2003). The percentage of wound healing was calculated of original wound size for each animal of group on predetermined days i.e. $1,4,7,10,13$ and 16 days postwounding for final analysis of results. Changes in wound area were calculated, giving an indication of the rate of wound contraction (Dash et al., 2009). The results are tabulated in Table 1.

Table 1: Effect of various extracts of $C$. rutidosperma roots on percentage (\%) wound closure (Excision Wound Model).

\begin{tabular}{clccccccc}
\hline \multirow{2}{*}{ Group Treatment } & \multirow{2}{*}{$\begin{array}{c}\text { Concen- } \\
\text { tration }\end{array}$} & \multicolumn{4}{c}{ Percentage (\%) wound closure. } & Epithelialization \\
\cline { 4 - 8 } & & - & $23.52 \pm 1.21$ & $51.92 \pm 1.71$ & $67.28 \pm 2.23$ & $75.24 \pm 1.18$ & $80.56 \pm 1.03$ & $24.06 \pm 0.62$ \\
Period (days)
\end{tabular}

Values are expressed as mean \pm S.E. $(n=6)$. All columns are significant using ANOVA.

${ }^{*} \mathrm{P}<0.05,{ }^{* *} \mathrm{P}<0.01$ when compared to control; Dunnet's t-test. 
Table 2: Effect of various extracts of $C$. rutidosperma roots on wound breaking strength (Incision Wound Model).

\begin{tabular}{cll}
\hline Group & \multicolumn{1}{c}{ Treatment } & \multicolumn{1}{c}{$\begin{array}{c}\text { Breaking } \\
\text { strength }(\mathrm{g})\end{array}$} \\
\hline I & Control & $325.23 \pm 26.08$ \\
II & Nitrofurazone $(0.2 \% \mathrm{w} / \mathrm{w})$ & $488.51 \pm 18.36^{* *}$ \\
III & Pet ether extract $(10 \% \mathrm{w} / \mathrm{w})$ & $332.26 \pm 10.23$ \\
IV & Chloroform extract $(10 \% \mathrm{w} / \mathrm{w})$ & $378.63 \pm 18.02^{*}$ \\
V & Methanol extract $(10 \% \mathrm{w} / \mathrm{w})$ & $457.20 \pm 12.58^{* *}$ \\
VI & Aqueous extract $(10 \% \mathrm{w} / \mathrm{w})$ & $383.83 \pm 10.82^{*}$ \\
\hline
\end{tabular}

Values are expressed as mean \pm S.E. $(n=6)$.

All columns are significant using ANOVA.

${ }^{*} \mathrm{P}<0.05$, ${ }^{* *} \mathrm{P}<0.01$ when compared to control; Dunnet's t-test.

\section{Incision Wound Model}

The rats were anaesthetized prior to and during creation of the wounds, with $1 \mathrm{ml}$ of intravenous ketamine hydrochloride $(10 \mathrm{mg} / \mathrm{kg})$. The dorsal fur of the animals was shaved with an electric clipper. A longitudinal paravertebral incision of $6 \mathrm{~cm}$ long was made through the skin and cutaneous tissue on the back as described by Dash et al. (2009). After the incision, the parted skin was sutured $1 \mathrm{~cm}$ apart using a surgical thread and curved needle. The wounds were left undressed. Extracts were topically applied to the wound once a day. The sutures were removed on $8^{\text {th }}$ post wound day and continued the application of the extract. The wound breaking strength was measured on the $10^{\text {th }}$ day evening after the last application (Reddy et al., 2002). The results are tabulated in Table 2.

\section{Statistical Analysis}

The data obtained in the studies were subjected to one way of analysis of variance (ANOVA) for determining the significant difference by using GraphPad InStat ${ }^{\circledR}$ software. The inter group significance was analyzed using Dunnet's t-test. A p-value $<0.05$ was considered to be significant. All the values were expressed as Mean \pm SEM.

\section{RESULTS}

The preliminary phytochemical screening of $C$. rutidosperma roots extracts showed presence of steroids and sterols, triterpenoids, flavonoids, saponins, tannins and phenolic substances, gums and mucilages, carbohydrates and proteins respectively in different extracts.
The results of wound healing effects of C. rutidosperma showed significant promotion of wound healing activity with both aqueous and methanol extracts in the excision and incision wound models. In excision wound model, the mean percentage closure of wound area was calculated on the 1, 4, 7, 10,13 and 16 post wounding days as shown in Table 1. The methanol extract treated animals showed faster epithelialisation of wound than the animals treated with aqueous roots extract. The percentage of wound closure was $100 \pm 00$ in the case of standard drug nitrofurazone on $13^{\text {th }}$ day of treatment, where as the methanol extract demonstrated similar effects on $16^{\text {th }}$ day. But the petroleum ether extracts did not reveal significant activity. The period of epithelialization was $17.16 \pm 1.04$ days for the methanol extract treated group of animals as against $13.18 \pm 1.47$ for the standards drug treated group.

In incision wound model (Table 2), the chloroform, methanol and aqueous extract treated animals showed significant increase in breaking strength $(378.63 \pm 18.02,457.2 \pm 12.58$ and $383.83 \pm 10.82$ respectively), when compared to the control (325.23 \pm 26.08$)$. The mean breaking strength was also significant in animals treated with standard drug nitrofurazone $(488.51 \pm 18.36)$ whereas the Pet-ether extract failed to produce significant effects. The methanol extract showed better activity $(\mathrm{p}<0.01)$ than the chloroform and aqueous extracts $(p<0.05)$.

\section{DISCUSSION}

The results of the present study revealed that, animals treated with methanol and aqueous extracts of $C$. rutidosperma showed faster rate of epithelialization in excision wound model compared to other extracts under study. The chloroform extract of the selected plant also produced promising results but the effects are seen to be of lesser extent than the corresponding methanol and aqueous extracts. The petroleum ether extract of $C$. rutidosperma did not produce significant results. The wound healing effects of the chloroform, methanol and aqueous extracts may be attributed to the presence of phytoconstituents like triterpenoids, tannins and flavonoids in the extracts which are known to promote the wound healing process mainly due to their antimicrobial property. Flavonoids and triterpenoids are also known to promote the wound- 
healing process mainly due to their astringent and antimicrobial property, which seems to be responsible for wound contraction and increased rate of epithelialisation (Karodi et al., 2009; James and Friday, 2010).

Increase in skin breaking strength and tissue breaking strength in incision wound model respectively indicated enhanced collagen maturation. The high collagen turnover which may be due to the activity of some phytoconstituents like flavonoids which are known to reduce lipid peroxidation not only by preventing or slowing the onset of cell necrosis but also by improving vascularity (Getie $e t$ al., 2002).

Thus, wound-healing property of the methanol and aqueous extracts may be attributed to the phytoconstituents they contain, which may be either due to their individual or additive effect that fastens the process of wound healing. The methanol extract of C. rutidosperma roots were found to possess better wound-healing property over other extracts. At this stage, it is difficult to say which component(s) of the extracts are responsible for the wound healing activity. However, further phytochemical studies are needed to isolate the active compound(s) responsible for these pharmacological activities.

\section{REFERENCES}

Karodi, R., Jadhav, M., Rub, R. and Bafna, A. (2009). Evaluation of the wound healing activity of a crude extract of Rubia cordifolia L. (Indian madder) in mice. International Journal of Applied Research in Natural Products, 2(2): 12-18.

Bidla, G., Titanji, V.P.K., Joko, B., Ghazali, G.E.I., Bolad, A. and Berzins, K. (2004). Antiplasmodial activity of seven plants used in African folk medicine. Indian Journal of Pharmacology, 36(4): 245-246.

Bose, A., Mondal, S., Gupta, J.K., Ghosh, T., Debbhuti, D. and $\mathrm{Si}, \mathrm{S}$. (2008). Antioxidant and free radical scavenging activities of Cleome rutidosperma. Oriental Pharmacy and Experimental Medicine, 8(2): 135-145. DOI

Burkill, H.M. (2004). The Useful Plants of West Tropical Africa, Vol. 5, Addenda Royal Botanic Gardens, United Kingdom, Pp. 686.

Dash, G.K., Mondal, S. and Murty, P.N. (2009). Evaluation of wound healing effects of Argemone mexicana Linn. leaves. Herbal Heritage. 1(3): 136-141.
Fulzele, S.V., Satturwar, P.M., Joshi, S.B. and Dorle, A.K. (2003). Wound healing activity of Chandanadi yamak in Rats Indian Journal of Pharmaceutical Sciences, 65(3): 301-304.

Getie, M., Gebre, M.T., Reitz, R. and Neubert, R.H. (2002). Evaluation of the release profiles of flavonoids from topical formulations of the crude extract of the leaves of Dodonea viscosa (Sapindaceae). Pharmazie, 57: 320-322. PMid:12061256

Harborne, J.B. (1984). Phytochemical method: A Guide to modern techniques of plant analysis, $2^{\text {nd }}$ ed., Chapman and Hall, New York, Pp. 85.

Kamath, J.V., Rana, A.C. and Chowdhury, A.R. (2003). Prohealing effect of Cinnamomum zeylanicum bark, Phytother Res, 17: 970-972. DOI PMid:13680838

Kiritikar, K.R. and Basu, B.D. (1991). Indian Medicinal Plants, $2^{\text {nd }}$ ed., Lalit Mohan Basu, Deharadun, India, Pp.181.

Kumar, B., Vijayakumar, M., Govindarajan, R. and Pushpangadan P. (2007). Ethnopharmacological approaches to wound healing-exploring medicinal plants of India. Journal of Ethnopharmacology, 114 (2): 103-113. DOI PMid:17884316

Mondal, S., Dash G.K., Acharyya S., Bose, A. and Singh, V. (2009). Hypoglycaemic activity from the roots of Cleome rutidosperma DC. Biomed, 4(1): 64-69.

Mondal, S., Dash G.K. and Bal S.K. (2009). Anthelmintic activity of Cleome rutidosperma DC. roots. Indian Drugs, 46(12): 47-49.

Morton, J.J. and Malone M.H. (1972). Evaluation of vulnerary activity by open wound procedure in rats, Arch. Int. Pharmacodyn. Ther., 196: 117-120.

James, O., and Friday, E.T. (2010). Phytochemical composition, bioactivity and wound healing potential of Euphorbia heterophylla (Euphorbiaceae) leaf extract, International Journal on Pharmaceutical and Biomedical Research, 1(1): 54-63.

Reddy, J.S., Rao, P.R. and Reddy, M.S. (2002). Wound Healing effects of Heliotropium indicum, Plumbago zeylanicum and Acalypha indica in rats., Journal of Ethnopharmacol, 79: 249-251. DOI

Trease, G.E., and Evans W.C. (1989). Pharmacognosy, $13^{\text {th }}$ ed., ELBS Publication, Delhi, India, Pp. 171.

Waterhouse, B., and Mitchell, A. (1998). Northern Australia Quarantine Strategy Weeds Target List, $2^{\text {nd }}$ ed., AQIS Miscellaneous Publication, Canberra. Pp. 29.

Widespread, J.M. (1972). Flora Malesiana Series I, Vol. 6, National Herbarium of the Netherlands, Netherlands, Pp. 61. 